\title{
Mammography: density equalizing mapping of the global research architecture
}

\author{
Dörthe Brüggmann ${ }^{1,2,3}$, Matthias Grimstein ${ }^{2}$, Christine Solbach ${ }^{1}$, Doris Klingelhöfer ${ }^{2}$, \\ Michael H. K. Bendels' ${ }^{2}$, Jenny Jaque ${ }^{3}$, David A. Groneberg ${ }^{2}$ \\ ${ }^{1}$ Department of Gynecology and Obstetrics, Goethe-University, Frankfurt, Germany; ${ }^{2}$ Institute of Occupational, Social and Environmental \\ Medicine, Frankfurt, Germany; ${ }^{3}$ Department of Obstetrics and Gynecology, Keck School of Medicine, University of Southern California, \\ California, USA
}

Correspondence to: Prof. Dörthe Brüggmann, MD, PhD. Department of Gynecology and Obstetrics, Goethe-University, Theodor Stern Kai 7, 60590 Frankfurt, Germany. Email: prevention@uni-frankfurt.de.

\begin{abstract}
Background: Since mammography belongs to the most important preventive techniques in modern medicine, this study maps the related worldwide research output, which encompasses quantitative and qualitative aspects of the scientific activity and socio-economic features.

Methods: The New Quality and Quantity Indices in Science (NewQIS) computing platform identified all mammography-specific articles in the Web of Science within two time periods, from 1900 to 2014 (P1) and from 2015 to 2020 (P2), a combination of density-equalizing mapping projections (DEMP) and socioeconomic benchmarking was applied for analysis.

Results: A total of 13,629 articles were retrieved. 8,744 articles were identified in P1 and 4,885 in P2. More than 100 articles were published annually since the 1980s. Regarding productivity and collaborative efforts, the United States was the leading nation in both evaluation periods. In our socioeconomic analysis, it was also ranked at the first place in P1 [72.68 mammography-related publications per GDP/capita (RGDP)]. The US was followed by the UK and Germany in P1 and by UK and India in P2. When population sizes were related to mammography research activities, Scandinavian countries and the Netherlands showed the highest research activity in P1 (e.g., Sweden: 31.89 publications per 1 million inhabitants). Gender analysis illustrated a relative dominance of female researchers in most countries with the exception of Japan.

Conclusions: The global mammography research activity over the last century is paralleled by strong international collaborative efforts and follows largely economic figures and prevalence rates but displays distinct differences in comparison to the research landscape of other biomedical entities.
\end{abstract}

Keywords: Density equalizing map; mammography; spatiotemporal analysis

Submitted Jul 22, 2019. Accepted for publication Sep 16, 2020.

doi: 10.21037/qims-19-774

View this article at: http://dx.doi.org/10.21037/qims-19-774

\section{Introduction}

In females, breast cancer is the most frequently diagnosed cancer and cause of death worldwide. The highest incidence rates are documented for high resource countries such as the United States and Canada as well as regions such as Western and Northern Europe (1-3). In contrast to Asia and sub-Saharan Africa, where the incidence numbers are the lowest, researchers associate epidemiological differences with distinct cultural, environmental and reproductive factors linked to the industrialization level such as lactation, fat intake, or fewer pregnancies $(1,4)$. Overall, known risk factors are well characterized; they include family or personal history of breast cancer, high breast density or genetic mutations among others $(1,4)$.

Prevention is extremely important in the field of breast 
cancer medicine. Breast cancer screening aims at reducing mortality and morbidity associated with advanced disease through early detection (5). The most common screening procedure is standard mammography, which was first described by the German Otto Kleinschmidt in 1927. In 1969, Gallager and Martin described the usefulness of mammography in detection of early stages of breast cancers coining the "concept of minimal breast cancer" $(6,7)$. Moscowitz published preliminary results for mammography as a screening tool (8). Today, mammography is offered by organized programs or through opportunistic screening, which typically provides exams upon request or embedded in routine health care (5). In November 2014, the International Agency for Research on Cancer (IARC) assessed the benefits and adverse effects of the different screening methods (5). They reported advantages for women aged 50 to 69 years due to mammographic screening (5). By contrast, randomized, controlled trials generally did not show a reduction in breastcancer mortality by regular breast self-examination (5).

From a global viewpoint, standard mammography may be regarded as one of the most important procedures to prevent death and disability from breast cancer. To date the debate about the harms and benefits of mammographic screening is ongoing. Numerous new topics have to be discussed such as tumor over-diagnosis and-treatment related to screening and the role of mammography in a modern era of increased public scrutiny and novel diagnostic tools such as tomosynthesis $(9,10)$. Hence, the international community needs to find answers to relevant questions in the area of "mammography", which underpins the necessity for further research. Since global research funds are limited, the assessment of the scientific performance is a prerequisite for the reasonable distribution of monetary support and human resources. In contrast to other areas of radiology (11-15) and the field of breast cancer research $(16,17)$, where 180,126 articles were published between 1945 and 2008, no concise studies have been reported on global activities of mammography research. To address this shortcoming, we used the New Quality and Quantity Indices in Science (NewQIS) computing platform (16-19) whose research aims are manifold and reviewed in great detail elsewhere (20). In short, this tool provides objective, transparent and reliable analyses of bibliometric parameters to assess the evolution of scientific productivity over distinct periods of time. Individual scientists or clinician-scientists, policy makers or funding institutions can utilize this data to match the past and current scientific output with future research interests or funding endeavors to address obvious needs. In this particular study, we employed the NewQIS platform to analyze the worldwide scientific productivity related to mammography with regard to (I) quantitative and qualitative assessments, (II) chronologic and geographic developments as well as (III) socio-economic, collaboration and gender aspects.

\section{Methods}

\section{NewQIS study}

The NewQIS computing platform was created by a multidisciplinary group of scientists to analyze scientific productivity regarding to a specific topic in a highly standardized approach as well as to visualize the results in global maps (20). Since its establishment in 2008/2009 NewQIS features have been discussed for three times by Nature and Nature Index blogs (21).

\section{Data source}

The high-quality Web of Science (WoS, Thomson Reuters) database allowed the quantitative analysis of research activity (e.g., the number of mammography-specific publications) as well as the assessment of qualitative aspects (e.g., citation rates) (22-24) by its unique citation report function.

\section{Search strategy}

We performed a TITLE search using the following search term: TITLE $=\left({ }^{*}\right.$ mammogra* OR (*tomosynthes* AND (breast OR mamma). Only documents classified as ARTICLES were included. Our search covered the two evaluation periods P1 from 1900 to 2014 and P2 from 2015 to 2020 in order to analyze the overall as well as the recent publication output.

\section{Data analysis and categorization}

The bibliographic details of mammography-related publications were sorted after retrieval of the file metadata and analyzed according to numerous criteria of interest (24-28). These criteria included year of publication, subject categories, and citations among others. From these data, country-specific h-indices were constructed. The h-index was developed by Jorge Hirsch in 2005 aiming to gauge scientific quality based on citations that an author's body of 
work receives $(29,30)$. Here, we used a modified h-index to estimate the recognition of the country-specific research output among the scientific community (31,32). The mammography-related articles could be attributed to more than one subject area. Hence, we could observe percentages exceeding $100 \%$ when we displayed the subject area analysis of all identified articles per country.

\section{Density-equalizing map projections}

A NewQIS core technique entails the generation of world maps depicting aspects of the investigated research output using density-equalizing map projections (DEMP) (32-34). All bibliometric metadata were transferred into a Microsoft ${ }^{\circledR}$ Access ${ }^{\circledR}$ database, which represented the core data source for all analyses. Based upon the density-equalizing principle algorithm created by Gastner and Newman (35), the variables of interest were visualized by density-equalizing map projections specifically for every country. Anamorphic cartograms were built utilizing the software "ArcGIS Cartogram" geoprocessing tool (https://www.arcgis. com). In these maps, territories of countries publishing mammography-related research were separated from each other and resized in proportion to selected criteria of interest such number of articles or citation counts.

\section{Economic analysis}

In order to provide more meaningful findings, we related each country's economic and demographic capabilities to its achievement in publishing. Gross domestic product (GDP) and population size were used as proxy measures for economic and human resources a country can utilize to create articles on mammography. We sourced economic key figures from the Central Intelligence Agency World Factbook and the International Monetary Fund (14,36). We related the publication output of the analyzed countries to their GDPs in 2015 for P1 and to their most recent GDPs in 2017 for P2.

\section{Analysis of mammography research collaborations}

To analyze global research collaborations, we downloaded the mean affiliations of authors listed in the identified articles. For each article, we extracted the countries of the respective co-authors, who collaborated for the article. These relationships were quantified (a collaboration between two authors was counted only once) and a circle diagram was created $(37,38)$. Vectors depict the number of joint publications between co-authors by their width and shade of grey.

\section{Gender assessment}

Author gender was analyzed. Therefore, we utilized a specific tool embedded in the NewQIS platform that collects first names and links names to the respective gender. This instrument was developed by the original creators of the NewQIS platform as an adaptive tool, which continuously integrates new data during each analysis. In our study, we identified all first names of authors publishing on mammography. An algorithm matched this collection with our source database so names were categorized into male, female, unknown and not assignable. Names of the last two categories (e.g., quoted as initials) were manually analyzed based on websites, corresponding addresses, and social networks. Only countries were considered where more than 60 authors as well as more than $50 \%$ of all authors were identified by gender.

\section{Creation of the key word analysis}

Aiming to define research foci in the area of mammography, we analyzed keywords attributed to all identified articles. A keyword needed to be identified at least 10 times to be taken into account. A database of all keywords was computed by the NewQIS platform and downloaded into the VOSviewer (https://www.vosviewer.com). This particular software allows cluster-analysis of the keywords as well as visualization of the results by constructing networks based on co-occurrence data. The clusters were color coded, and the vectors between the key words represent the co-occurrence of keywords in the identified articles.

\section{Results}

\section{Density equalizing mapping}

From 1900 to 2014 (P1), we identified 8,744 articles (n) that were issued on mammography. 4,885 articles were published from 2015 to 2020 (P2). In total, this added up to 13,629 articles in both evaluation periods.

The first mammography-specific article was published in 1937. For the first 80 years of the $20^{\text {th }}$ century we found a very slow increase of the annual publication output, which exceeded more than 100 annual articles in the later 1980s. From 2011 onwards, more than 400 annual articles were 


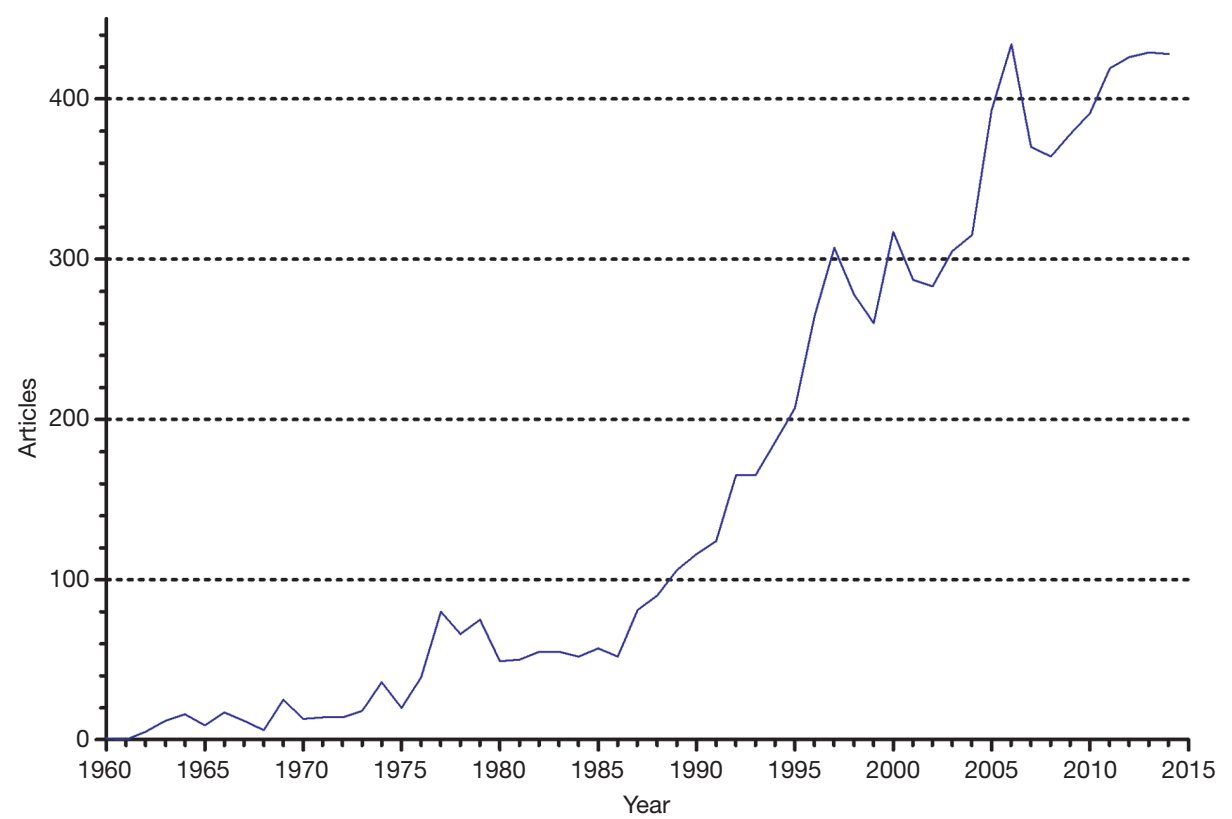

Figure 1 Global mammography research activity (1900 to 2014). Number of published items per year. Before 1960s, no considerable annual publication output was recorded so the graph starts in 1960.

identified (Figure 1). In the second evaluation period, the annual article number increased to 1,030 articles in 2015 and 1,029 articles in 2016. Thereafter, the yearly number of articles decreased to 774 in 2017 and has remained below 1,000 per year since then.

In the country specific analyses, authors from 83 countries were identified, who published mammography articles during P1. This number increased to 101 for P2. From the total amount of articles in $\mathrm{P} 1, \mathrm{n}=8,513$ articles $(97.36 \%)$ could be assigned to a country of origin, and in $\mathrm{P} 2, \mathrm{n}=4,528(92.70 \%)$ respectively. US-American authors (authors who stated "United States of America" in their affiliation) were most productive and published the highest number of mammography-related papers in both evaluation periods (P1: $\mathrm{n}=3,983, \mathrm{P} 2: 1,683)$. In P1, they were followed by the United Kingdom (UK) with 711 articles (n), Germany ( $\mathrm{n}=661)$, Canada $(\mathrm{n}=507)$, and Italy $(\mathrm{n}=425)$. DEMP analysis demonstrated a distortion of the world map with a distinct focus on Northern America, Western Europe, and Australia (Figure $2 A$ and Table 1). In P2, the US $(n=1,683)$ was also leading the field of most productive countries and followed by the UK $(\mathrm{n}=377)$. In contrast to P1, the order in P2 changed to the following: India $(n=273)$, Australia $(\mathrm{n}=268)$, China $(\mathrm{n}=251)$. Here, DEMP analysis represented the corresponding increase of publication numbers on mammography in India and China (Figure 2B,
Table 1).

The analysis of total mammography-specific citations (c) also demonstrated a leading US-American position in both evaluation periods (P1: c =120,321, P2: c =8311). In P1, the US were followed by Canada $(c=18,316)$ the UK (c =15,996), Sweden ( $c=13,638)$ and the Netherlands ( $c=9,267)$, (Figure $3 A$ ). In P2, the US were followed by Australia ( $c=1916)$, the UK ( $c=1,829)$, the Netherlands ( $c$ $=1378)$ and Italy $(\mathrm{c}=1,064)$ (Figure $3 B)$.

As citation rate (CR), we calculated the citation count per mammography-related articles that authors from a specific country gained (with a minimum of 30 published articles). Here, Sweden was leading in P1 with 43.99 citations per article, followed by Canada ( $\mathrm{CR}=36.13)$, the Netherlands $(\mathrm{CR}=31.52)$ and the US $(\mathrm{CR}=30.21)$ (Figure $4 A)$. The analysis of $\mathrm{P} 2$ showed the following order: Denmark (CR $=8.32)$, the Netherlands $(\mathrm{CR}=8.06)$, Austria $(\mathrm{CR}=7.22)$, and Portugal (CR $=7.22$ ) (Figure $4 B$ ).

The analysis of the mammography-specific h-index for each country also showed in P1 a leading position of the US and with a modified h-index of 135 , followed by Canada (h-index =69), the UK (h-index =56), Sweden (h-index $=54$ ), and the Netherlands (h-index =45)]. P2 showed the following ranking: US (h-index $=36$ ), Australia (h-index $=24)$, UK (h-index $=22$ ), Netherlands (h-index $=20$ ), and Italy (h-index $=18$ ). We also identified the 16 articles with 

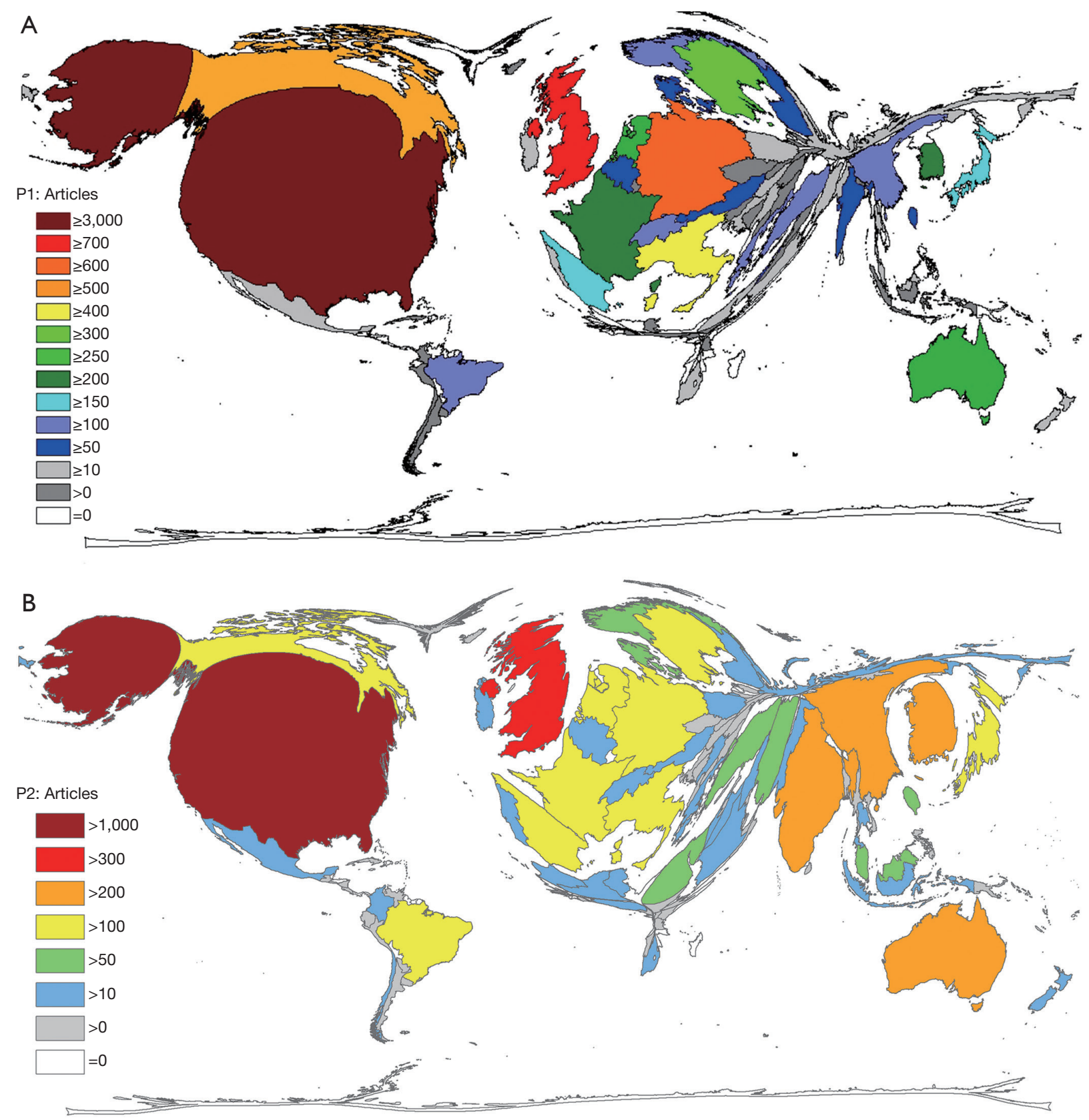

Figure 2 Global scientific productivity on mammography. Density equalizing, colours and territorial sizes indicate numbers of related articles per country. (A) Global mammography research activity from 1900 until 2014 (P1). (B) Global mammography research activity from 2015 until 2020 (P2).

more than 500 citations, which were published from 1985 onwards (Table 2).

\section{Socio-economic analysis of mammography research}

First, the country-specific mammography publications were related to the population size in million inhabitants $\left(\mathrm{R}_{\mathrm{POP}}\right)$. In P1, Sweden was ranked as the most active high-income country with $\mathrm{R}_{\mathrm{POP}}=31.89$ publications per inhabitant, followed by Norway $\left(R_{\mathrm{POP}}=28.79\right)$, the Netherlands $\left(\mathrm{R}_{\mathrm{POP}}=17.43\right)$, Finland $\left(1 \mathrm{R}_{\mathrm{POP}}=6.73\right)$ and Denmark $\left(\mathrm{R}_{\mathrm{POP}}\right.$ $=16.01)$ (Figure 3$)$. The US $\left(\mathrm{R}_{\mathrm{POP}}=12.49\right)$ and the UK $\left(\mathrm{R}_{\mathrm{POP}}\right.$ 
Table 1 Global mammography research productivity in P1 (1900 to 2014) and P2 (2015 to 2020)

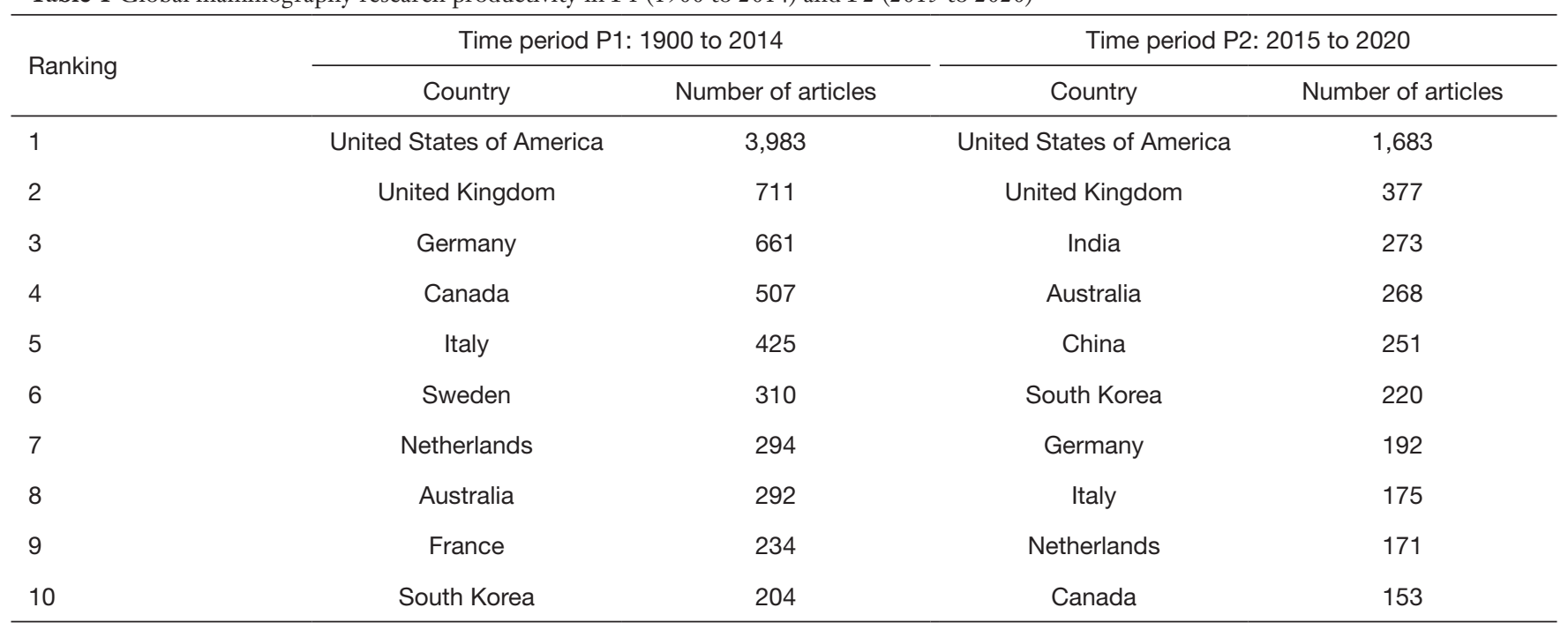

Number of published items per year.

$=11.15)$ were ranked at $11^{\text {th }}$ and $12^{\text {th }}$ position. For China, we identified 0.09 publications per inhabitant while Brazil was characterized by a $\mathrm{R}_{\mathrm{POP}}$ of 0.62 , and India of a $\mathrm{R}_{\mathrm{POP}}$ of 0.05 mammography-related publications per inhabitant, respectively (Table 3). In P2, Norway is ranked first $\left(\mathrm{R}_{\mathrm{POP}}=\right.$ $17.12)$, followed by Sweden $\left(\mathrm{R}_{\mathrm{POP}}=14.40\right)$, Australia $\left(\mathrm{R}_{\mathrm{POP}}\right.$ $=11.91)$, the Netherlands $\left(\mathrm{R}_{\mathrm{POP}}=10.14\right)$, and Denmark $\left(\mathrm{R}_{\mathrm{POP}}\right.$ =9.53) (Table 4).

The gross domestic product (GDP) per capita $\left(\mathrm{R}_{\mathrm{pC}}\right)$ was used as a marker of the economic strength in relation to the population and related to the country-specific mammography publications $\left(\mathrm{R}_{\mathrm{GDP}}\right)$ : In $\mathrm{P} 1$, the US was at the top position of all analysed high-income countries with an $\mathrm{R}_{\mathrm{pC}}$ of 72.68 articles, followed by the UK $\left(\mathrm{R}_{\mathrm{pC}}=18.86\right)$, and Germany $\left(\mathrm{R}_{\mathrm{pC}}=14.79\right)$ (Table 3). In P2, the leading countries regarding the evaluation of $\mathrm{R}_{\mathrm{pC}}$ were as follows: India $\left(\mathrm{R}_{\mathrm{pC}}=47.07\right)$, the US $\left(\mathrm{R}_{\mathrm{pC}}=30.71\right)$, and China $\left(\mathrm{R}_{\mathrm{pC}}\right.$ $=19.46)$ (Table 4).

The countries' GDP in 1,000 billion (bn) USD served as the parameter of the total economic strength. It was related to mammography research output to create the ratio $\mathrm{R}_{\mathrm{GDP}}$ : In $\mathrm{P} 1$, the ranking of high-income countries was led by Greece with an average $R_{\mathrm{GDP}}$ of 600.84 . It was followed by Sweden with an $\mathrm{R}_{\mathrm{GDP}}$ of 543.76 and the Netherlands with an $\mathrm{R}_{\mathrm{GDP}}$ of 339.34 . The US was characterized by an $\mathrm{R}_{\mathrm{GDP}}$ of 228.65 and the UK by an $\mathrm{R}_{\mathrm{GDP}}$ of 241.43 (Figure 4 , Table 3). For upper middle-income countries, Turkey was ranked first with a $\mathrm{R}_{\mathrm{GDP}}$ of 148.86 . Brazil reached an $\mathrm{R}_{\mathrm{GDP}}$ of 53.12. The highest ranked lower middle-income country was India with an $\mathrm{R}_{\mathrm{GDP}}$ of 29.76 (Table 3). In $\mathrm{P} 2$, Sweden was the leading country with $\mathrm{R}_{\mathrm{GDP}}=245.57$, followed by the upper middle income-country Malaysia $\left(\mathrm{R}_{\mathrm{GDP}}=211.07\right)$, and the lower middle income-country Egypt ranked third $\left(\mathrm{R}_{\mathrm{GDP}}\right.$ $=202.51)$ followed by the Netherlands $\left(\mathrm{R}_{\mathrm{GDP}}=197.37\right)$ and Australia $\left(\mathrm{R}_{\mathrm{GDP}}=185.60\right)$ (Table 4).

\section{Analysis of mammography research subject areas}

The majority of articles $(n=3,908)$ was attributed to the subject area of "Radiology, Nuclear Medicine \& Medical Imaging" during both investigated time periods. For $\mathrm{P} 1$, it was followed by "Oncology" $(\mathrm{n}=1,678)$, "Public, Environmental \& Occupational Health" (n=1,018). "Obstetrics \& Gynecology" (n=467) and "Surgery" (n=421). A remarkable finding was the prominent increase of articles attributed to "Public, Environmental \& Occupational Health" between 1965 and 2014 (Figure 5A).

When a country-specific analysis for the subject area activities was performed for the ten most active countries, researchers working in Australia, Canada and the US seemed to focus increasingly on Public health-related topics within mammography research. It was a striking finding that Australia was identified as the only country, in which mammography research was not clearly dominated by the field of "Radiology" (Figure 5B).

Key word analysis led to six different clusters of key words (Figure 6). Most popular scientific foci of mammography publications were areas such as digital 

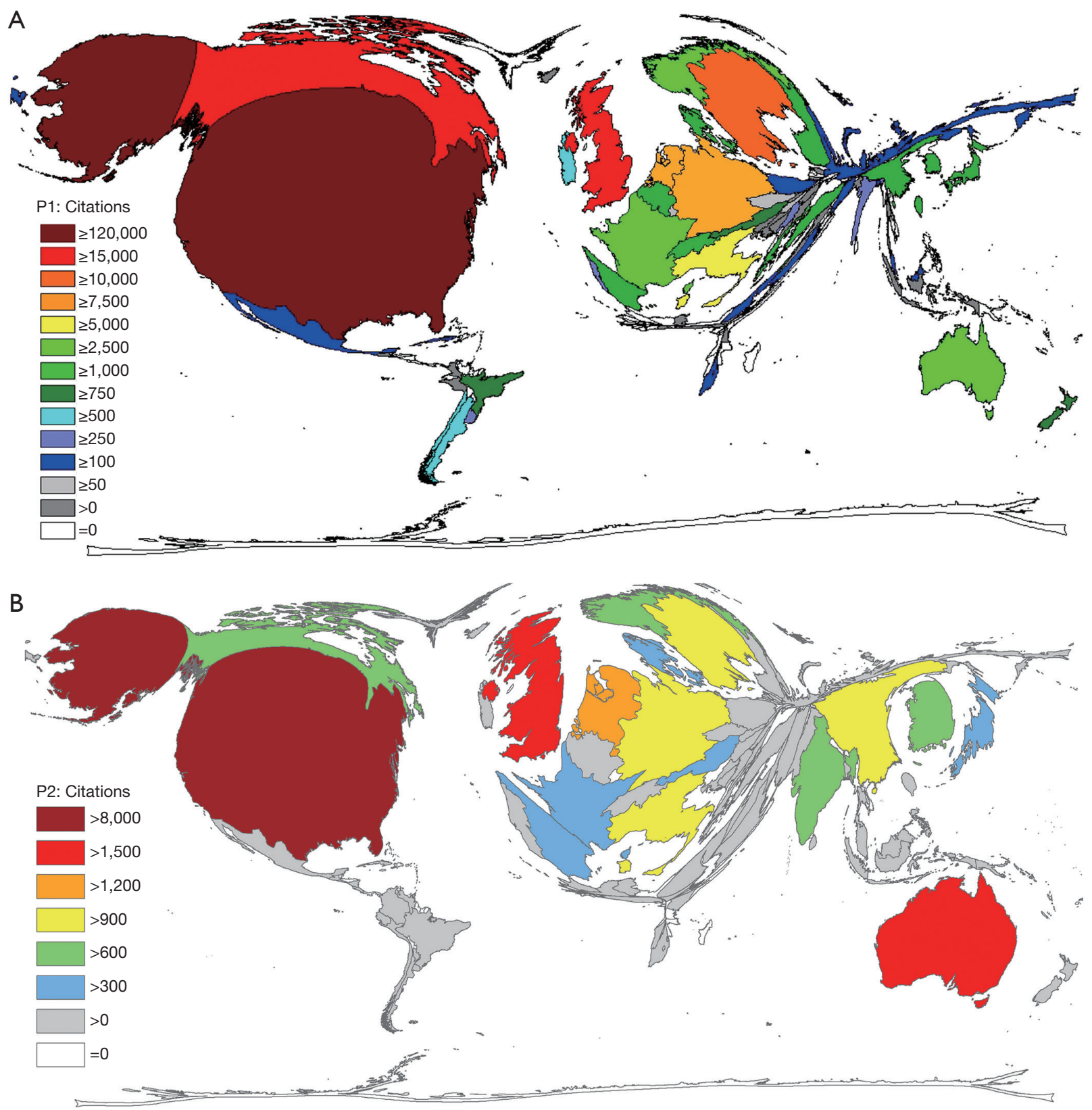

Figure 3 Mammography research quality as represented by the total citation number. (A) Density equalizing map of the total number of mammography-specific citations per country from 1900 until 2014 (P1). (B) Density equalizing map of the total number of mammographyspecific citations per country from 2015 until 2020 (P2).

mammography, mammographic density, or screening.

\section{International mammography collaborations}

In total, 1,000 international collaborations $(11.75 \%$ of all articles) were identified in $\mathrm{P} 1$ and 905 collaborations
$(20.00 \%)$ in $\mathrm{P} 2$. In P1, US-American authors were involved in 622 collaborative articles with other countries. Researchers based in the UK participated in 206 joint articles and Canadian authors worked on 186 collaborations. These three countries and Norway also led the bilateral collaborations (Figure 7). The second evaluation period 

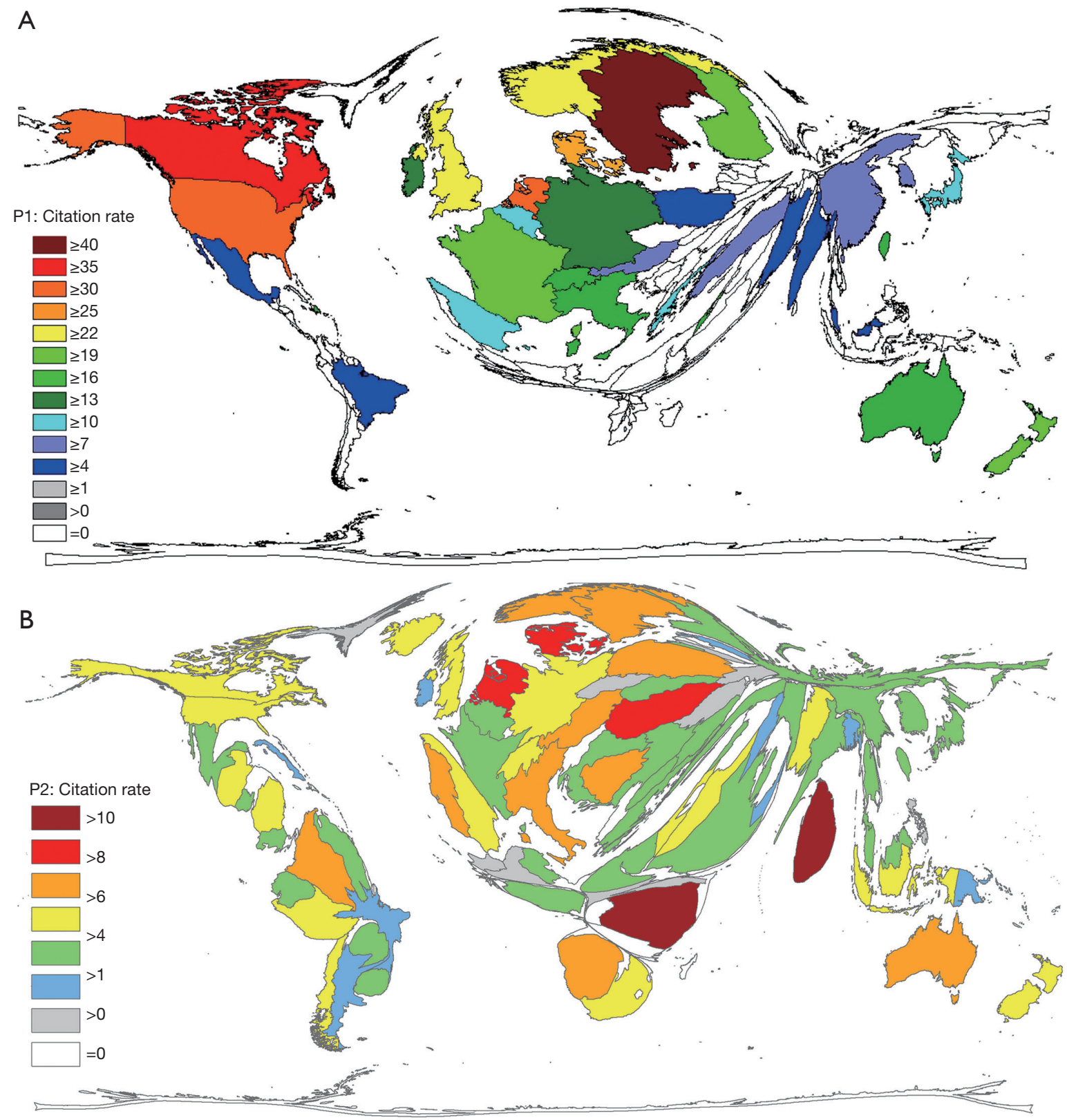

Figure 4 Mammography research quality as represented by the citation rate. (A) Density equalizing map of the total number of mammography-specific citation rates (threshold of 30 publications per country) per country from 1900 until 2014 (P1). (B) Density equalizing map of the total number of mammography-specific citation rates (threshold of 30 publications per country) per country from 2015 until $2020(\mathrm{P} 2)$.

showed the most active partnership on mammography between the US and China with $n=67$ collaboration articles.

\section{Gender analysis}

In order to assess gender aspects in mammography research, subject areas and country were analysed concerning the gender of participating authors. For reasons of validity, this analysis war restricted to P1. Subject areas with a technical focus were found to be dominated by men (i.e., "Engineering" or "Medical Informatics") while female authors dominated the fields of "Public, Environmental and 
Table 2 Articles with more than 500 citations, published from 1985 onwards

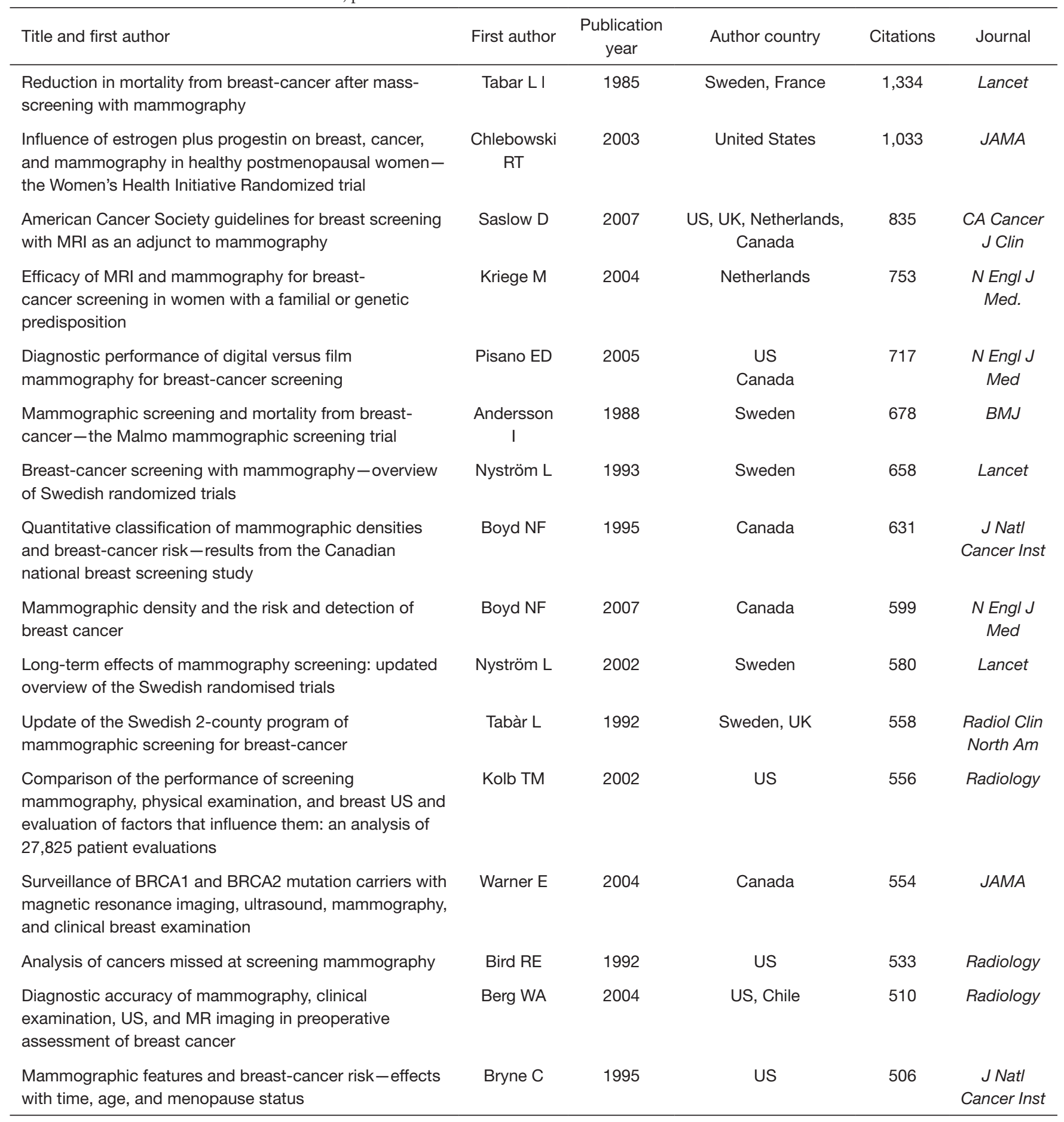

Occupational health" and "Women's Studies" (Figure 8A). The majority of female authors involved in mammography research were affiliated with research institutions located in the US (934 female vs. 775 male), Canada (113 female $v s$.
83 male) and Australia (63 female vs. 53 male). By contrast, male authors dominated the scientific community related to mammography in the UK (105 male $v s .95$ female), or in Germany (100 male vs. 60 female). The highest gender 
Table 3 Evaluation period P1 (1900 to 2014): socio-economic analysis of mammography research of the most active regions

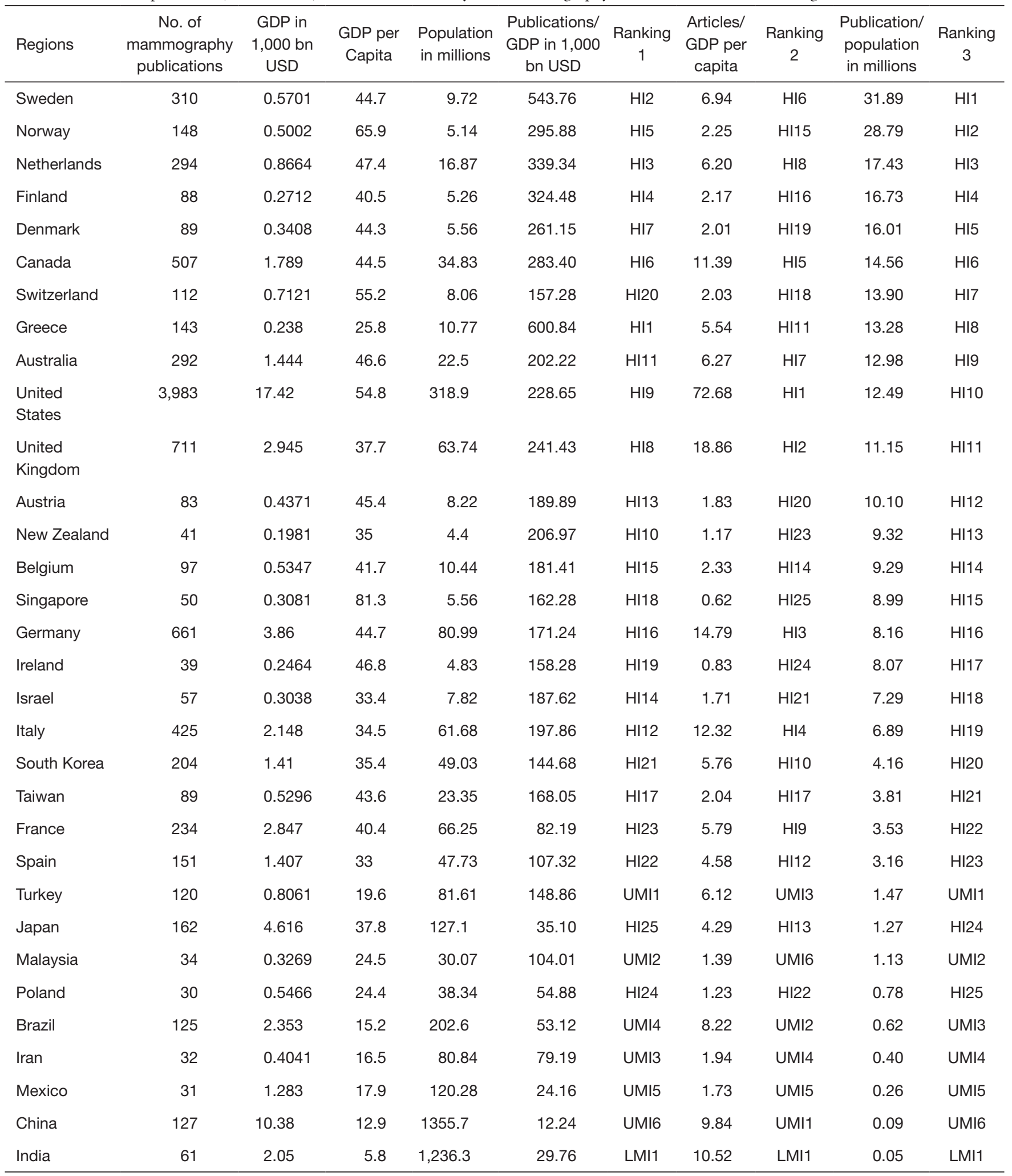

Sources for GDP (Current prices in 1,000 bn US Dollars) and GDP per capita (current prices in 1,000 US Dollars): IMF. HI, high income country; UMI, upper middle-income country; LMI, lower middle-income countries. 
Table 4 Evaluation period P2 (2015 to 2020): socio-economic analysis of mammography research of the most active regions

\begin{tabular}{|c|c|c|c|c|c|c|c|c|c|c|}
\hline Regions & $\begin{array}{c}\text { No. of } \\
\text { mammography } \\
\text { publications }\end{array}$ & $\begin{array}{l}\text { GDP in } \\
1,000 \text { bn } \\
\text { USD }\end{array}$ & $\begin{array}{c}\text { GDP per } \\
\text { capita }\end{array}$ & $\begin{array}{l}\text { Population } \\
\text { in millions }\end{array}$ & $\begin{array}{c}\text { Articles/GDP } \\
\text { in } 1,000 \text { bn } \\
\text { USD }\end{array}$ & $\begin{array}{c}\text { Ranking } \\
1\end{array}$ & $\begin{array}{l}\text { Articles/ } \\
\text { GDP per } \\
\text { capita }\end{array}$ & $\begin{array}{c}\text { Ranking } \\
2\end{array}$ & $\begin{array}{l}\text { Articles/ } \\
\text { population } \\
\text { in millions }\end{array}$ & $\begin{array}{c}\text { Ranking } \\
3\end{array}$ \\
\hline Sweden & 140 & 0.57 & 44.70 & 9.72 & 245.57 & HI1 & 3.13 & HI12 & 14.40 & HI2 \\
\hline Australia & 268 & 1.44 & 46.60 & 22.50 & 185.60 & HI3 & 5.75 & HI4 & 11.91 & HI3 \\
\hline Denmark & 53 & 0.34 & 44.30 & 5.56 & 155.52 & $\mathrm{HI} 7$ & 1.20 & HI18 & 9.53 & HI5 \\
\hline Finland & 40 & 0.27 & 40.50 & 5.26 & 147.49 & HI9 & 0.99 & HI21 & 7.60 & HI6 \\
\hline Switzerland & 49 & 0.71 & 55.20 & 8.06 & 68.81 & HI19 & 0.89 & HI22 & 6.08 & $\mathrm{HI7}$ \\
\hline Austria & 46 & 0.44 & 45.40 & 8.22 & 105.24 & $\mathrm{HI} 13$ & 1.01 & $\mathrm{HI} 20$ & 5.60 & $\mathrm{HI} 10$ \\
\hline $\begin{array}{l}\text { United } \\
\text { States }\end{array}$ & 1,683 & 17.42 & 54.80 & 318.90 & 96.61 & HI14 & 30.71 & $\mathrm{HI} 1$ & 5.28 & HI11 \\
\hline South Korea & 220 & 1.41 & 35.40 & 49.03 & 156.03 & HI6 & 6.21 & HI3 & 4.49 & $\mathrm{HI} 12$ \\
\hline Canada & 153 & 1.79 & 44.50 & 34.83 & 85.52 & HI16 & 3.44 & HI10 & 4.39 & $\mathrm{HI} 13$ \\
\hline Belgium & 45 & 0.53 & 41.70 & 10.44 & 84.16 & $\mathrm{HI} 17$ & 1.08 & HI19 & 4.31 & $\mathrm{HI} 14$ \\
\hline Greece & 37 & 0.24 & 25.80 & 10.77 & 155.46 & HI8 & 1.43 & $\mathrm{HI} 14$ & 3.44 & HI15 \\
\hline Malaysia & 69 & 0.33 & 24.50 & 30.07 & 211.07 & UMI1 & 2.82 & UMI5 & 2.29 & UMI1 \\
\hline France & 133 & 2.85 & 40.40 & 66.25 & 46.72 & HI22 & 3.29 & $\mathrm{HI} 11$ & 2.01 & HI21 \\
\hline Saudi Arabia & 41 & 0.75 & 52.80 & 27.34 & 54.49 & $\mathrm{HI} 20$ & 0.78 & $\mathrm{HI} 23$ & 1.50 & $\mathrm{HI} 22$ \\
\hline Japan & 135 & 4.62 & 37.80 & 127.10 & 29.25 & $\mathrm{HI} 23$ & 3.57 & HI9 & 1.06 & $\mathrm{HI} 23$ \\
\hline Turkey & 82 & 0.81 & 19.60 & 81.61 & 101.72 & UMI3 & 4.18 & UMI4 & 1.00 & UMI2 \\
\hline Iran & 73 & 0.40 & 16.50 & 80.84 & 180.65 & UMI2 & 4.42 & UMI3 & 0.90 & UMI3 \\
\hline Brazil & 144 & 2.35 & 15.20 & 202.60 & 61.20 & UMI4 & 9.47 & UMI2 & 0.71 & UMI4 \\
\hline Egypt & 58 & 0.29 & 11.10 & 86.89 & 202.51 & LMI1 & 5.23 & LMI2 & 0.67 & LMI1 \\
\hline Mexico & 47 & 1.28 & 17.90 & 120.28 & 36.63 & UMI5 & 2.63 & UMI6 & 0.39 & UMI5 \\
\hline India & 273 & 2.05 & 5.80 & 1236.30 & 133.17 & LMI2 & 47.07 & LMI1 & 0.22 & LMI2 \\
\hline China & 251 & 10.38 & 12.90 & $1,355.70$ & 24.18 & UMI6 & 19.46 & UMI1 & 0.19 & UMI6 \\
\hline
\end{tabular}

Sources for GDP (current prices in 1,000 bn US Dollars) and GDP per capita (current prices in 1,000 US Dollars. 


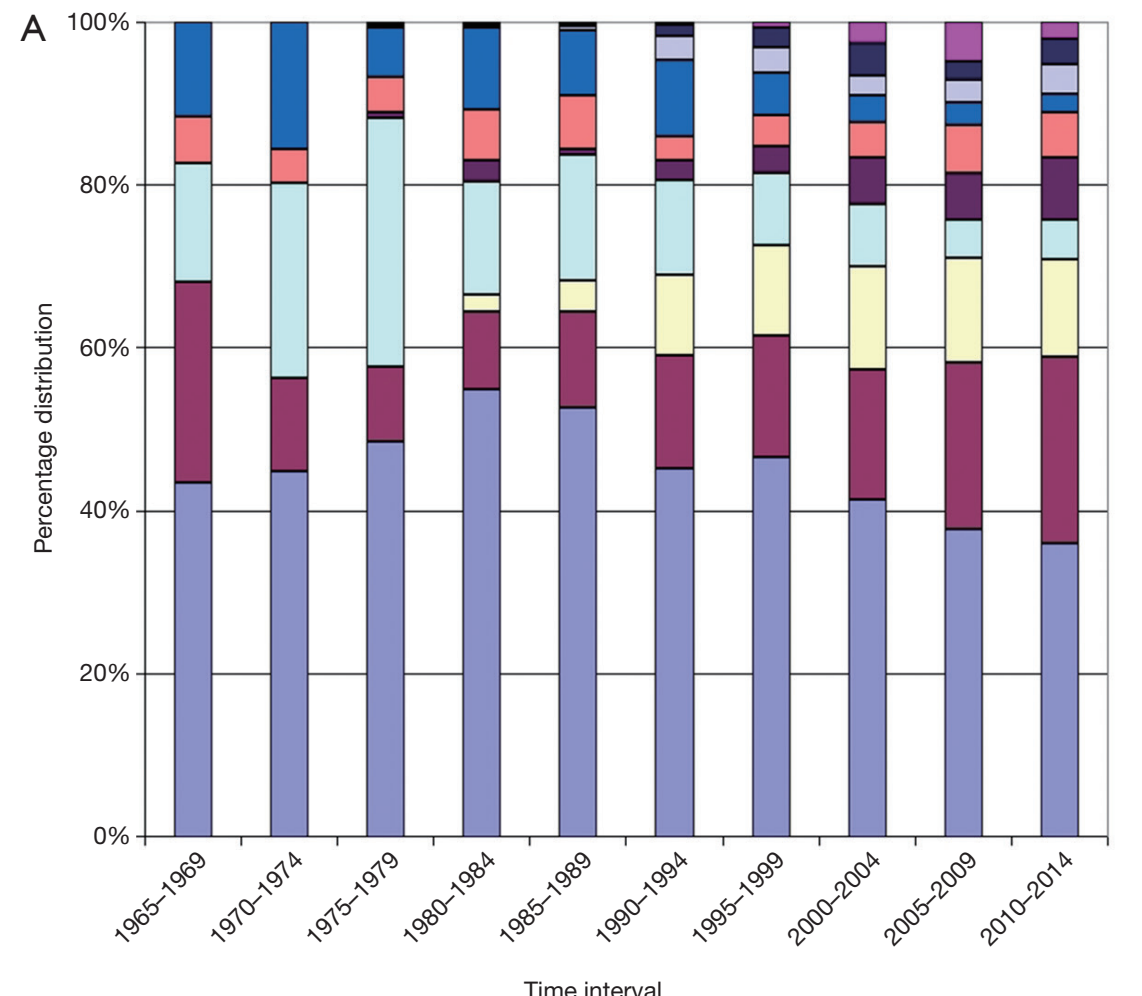

$\square$ Computer Science

- Health Care Sciences \& Services

$\square$ Nuclear Science \& Technology

$\square$ Surgery

$\square$ Obstetrics \& Gynecology

घEngineering

$\square$ General\& Internal Medicine

$\square$ Public, Environmental \& Occupational Health

$\square$ Oncology

$\square$ Radiology, Nuclear Medicine \& Medical Imaging

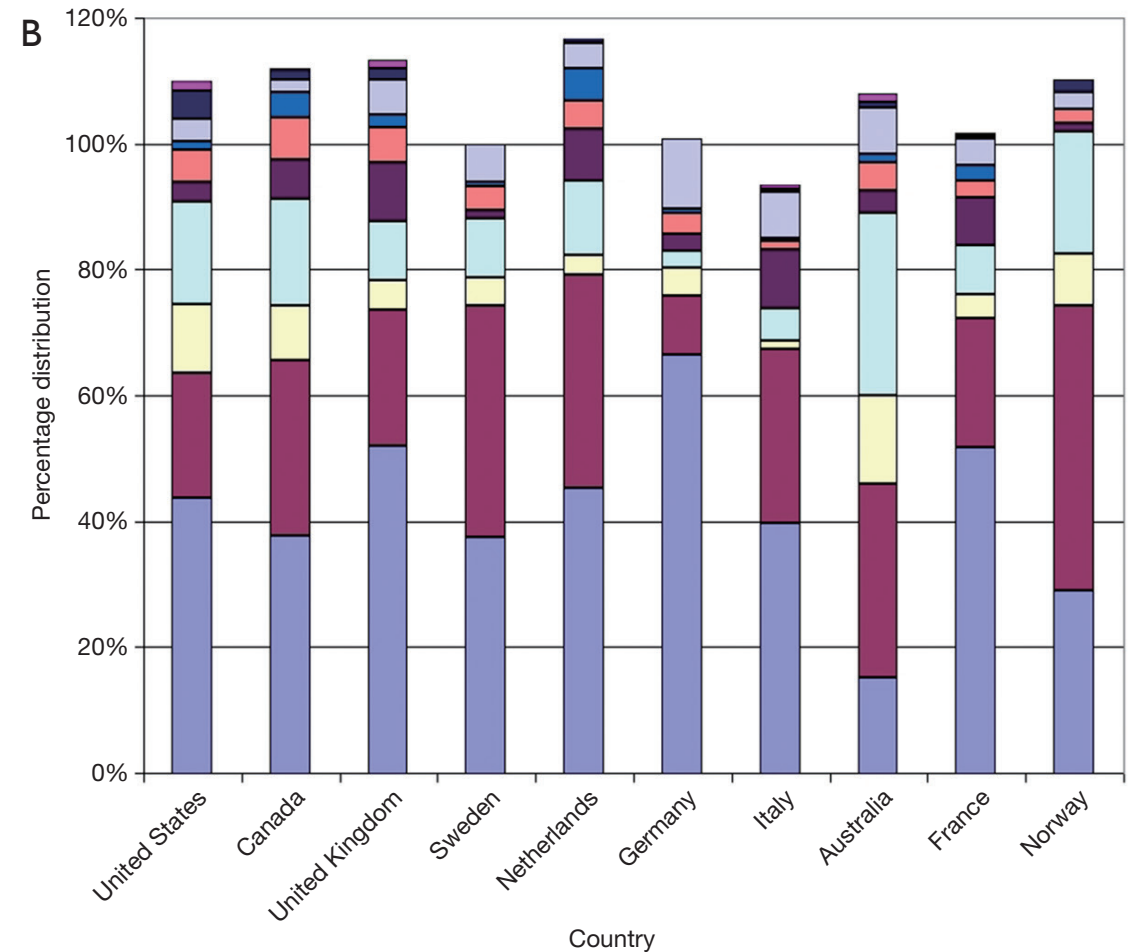

$\square$ Psychology

- Health Care sciences \& Services

$\square$ Obstetrics \& Gynecology

口Imaging science \& Photographic Technology

$\square$ Surgery

Engineering

$\square$ Public, Environmental \& Occupational Health

$\square$ General \& Internal Medicine

$\square$ Oncology

$\square$ Radiology, Nuclear Medicine \& Medical Imaging

Figure 5 Subject area analysis of mammography research, evaluation period (1900 to 2014). (A) Relative proportions of the most assigned subject areas in 5-year intervals between 1965 and 2014. (B) Relative proportions of the most assigned subject areas in most active countries. 


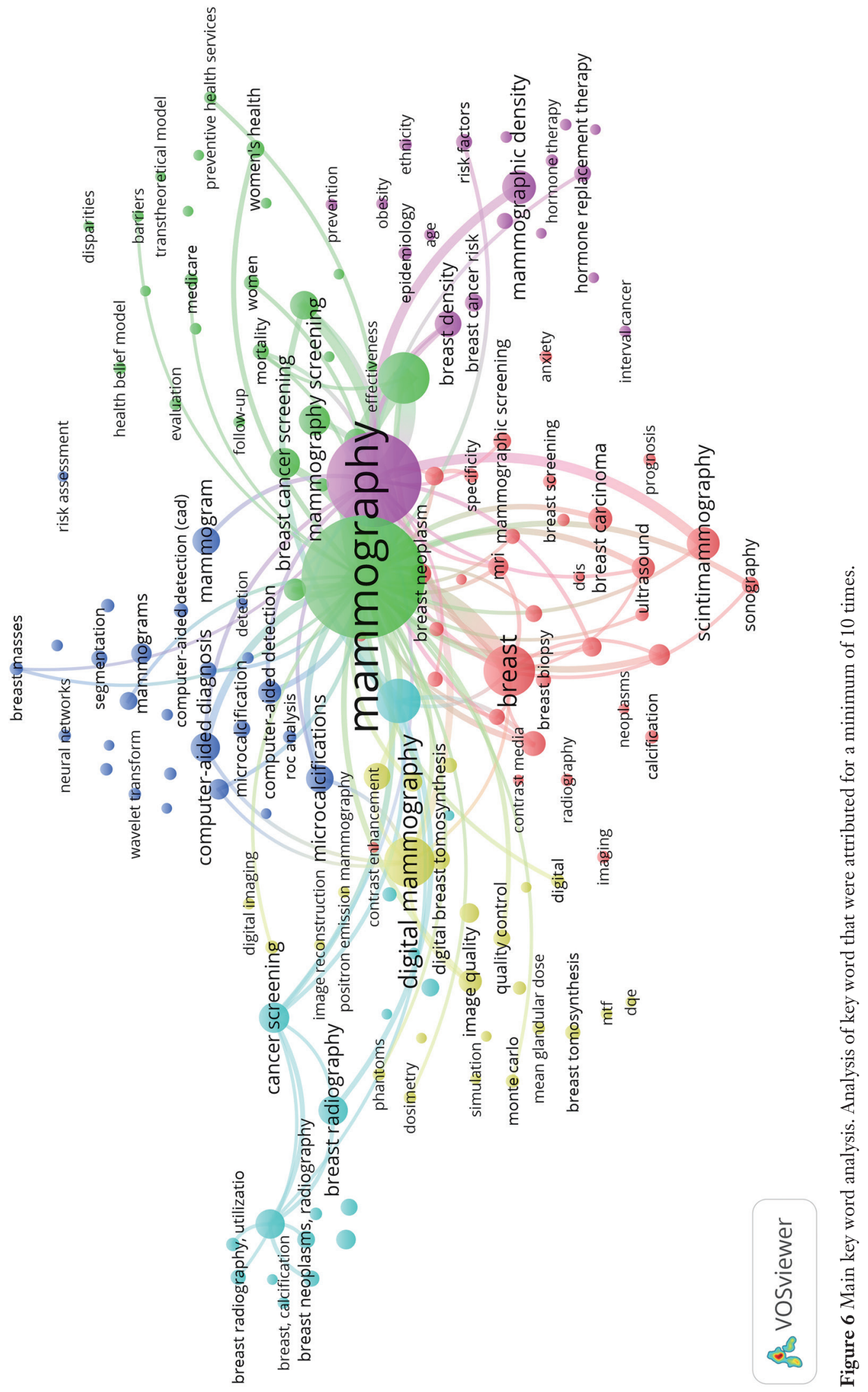




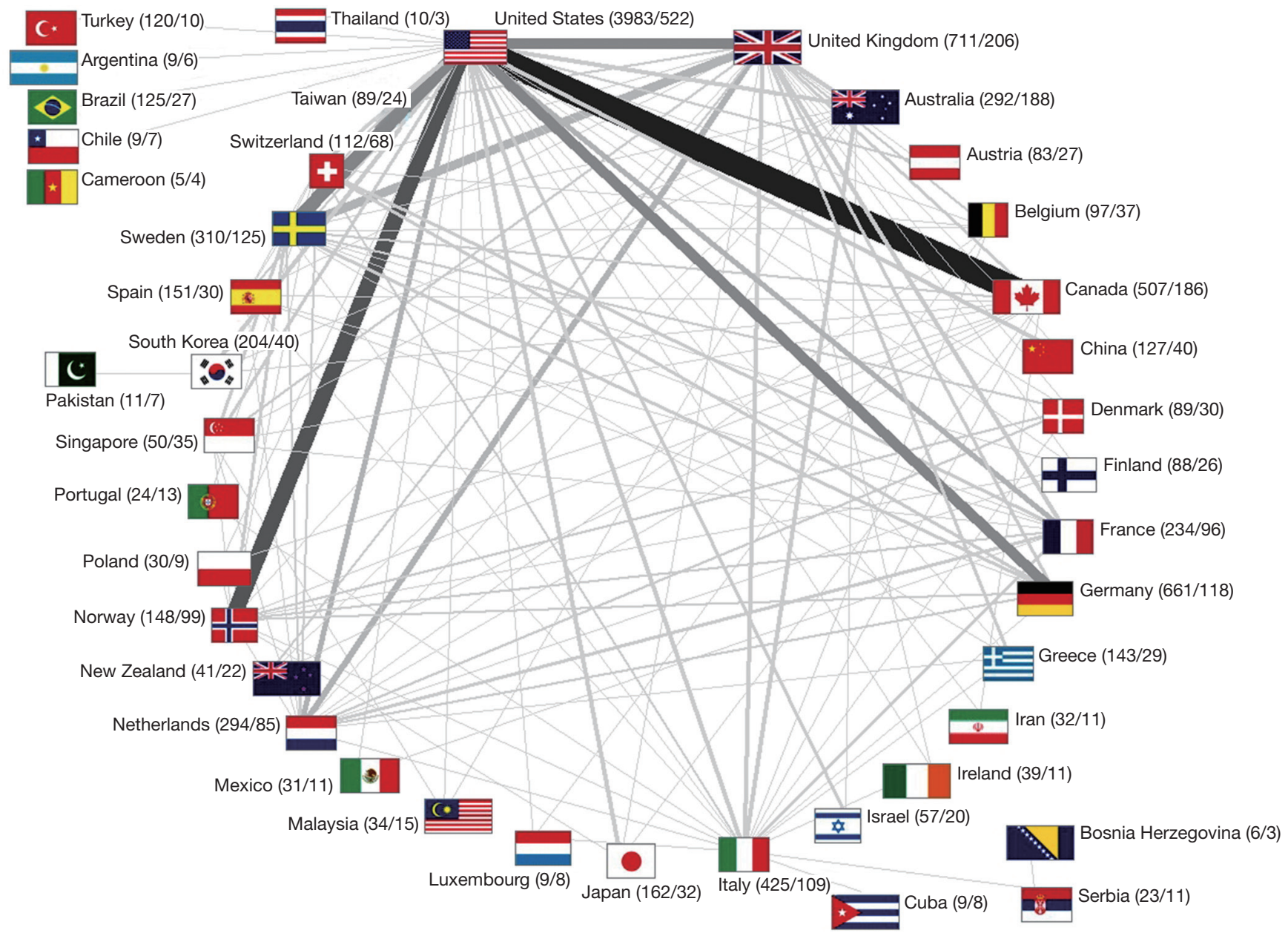

Figure 7 Mammography research collaborations between regions. Greyscale and bar thickness indicate intensity of collaborations, Number in brackets (total publication numbers/number of collaborative publications), Threshold: at least 5 collaborations of a single country, evaluation period (1900 to 2014).

imbalance toward male authors was present in Japan with 113 male vs. 39 female authors (Figure 8B).

\section{Discussion}

In this study, we investigated the global publication output on "mammography" since 1900 and extracted more than 13,000 articles from the WoS to perform an analysis of quantitative and qualitative outcomes, chronological and geographical developments, collaborative networks, socioeconomic indicators, and gender aspects in a reliable and standardized way. Despite this strength of being the first study of its kind, some limitations have to be addressed. In this context, the WoS is biased towards journals publishing in English. Therefore, our approach could not identify all existing articles issued on mammography since 1900, which is illustrated by the fact that the initial report of the technique was not found by our search. Kleinschmidt published his findings in a German book chapter. Since we focused our search on English journals as well as on "articles" to increase the accuracy of the search we did not identify this trailblazer publication but found the first English "mammography" article in 1937. Although an underestimation of non-English articles exists in our study, it might be limited since high quality data is usually published in international journals, indexed in the WoS and therefore included in our search. Further, we gauged the scientific quality of the identified articles by citationbased parameters. This approach has its limitations because citation numbers rather mirror the recognition level of a 

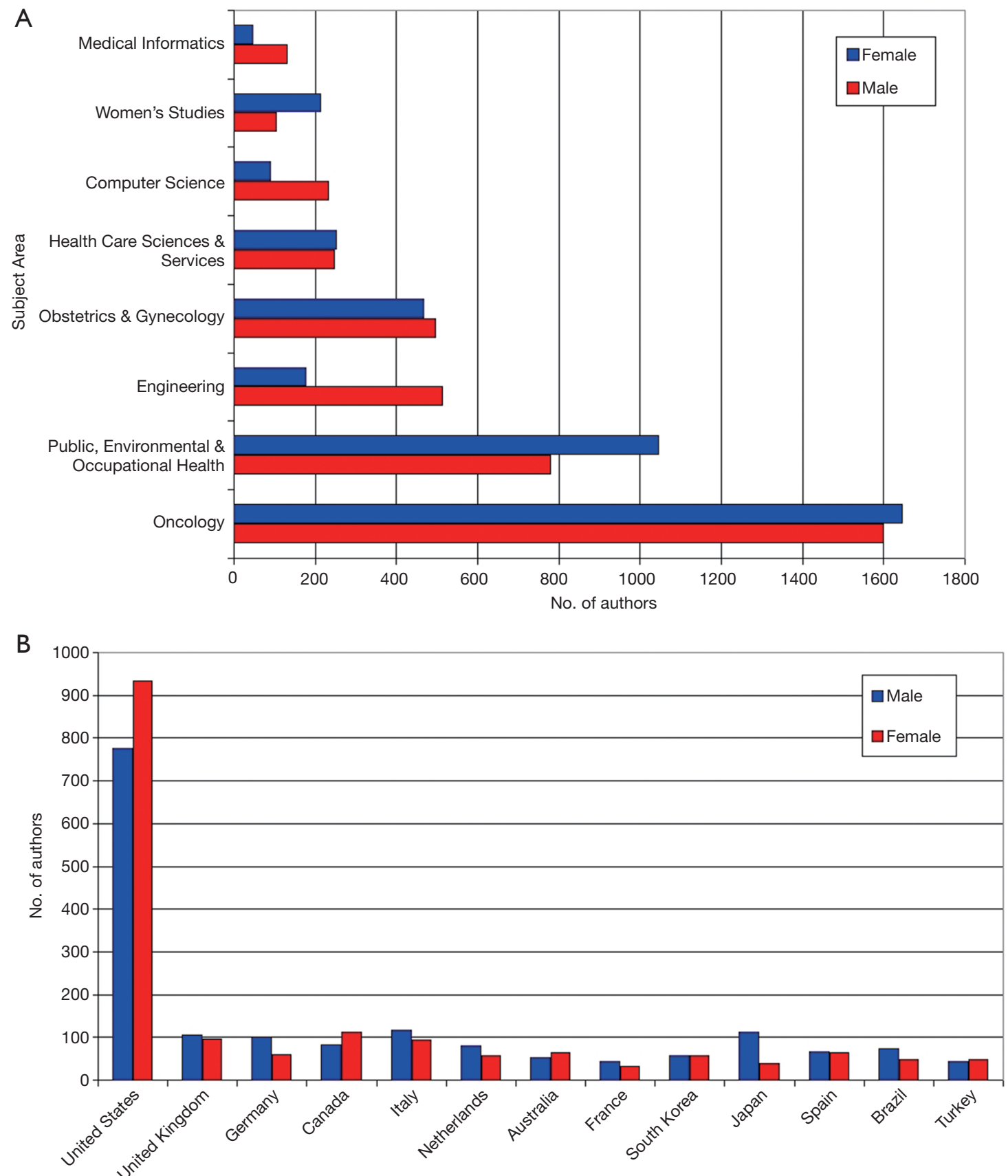

Country

Figure 8 Analysis of the gender of authors publishing on mammography. (A) Subject areas of articles published by authors of a respective gender. (B) Gender of authors analysed by originating country.

publication within the research community than quantify the true scientific quality of the article. Also, another considerable limitation of our method is the difficult reproducibility of our approach since the NewQIS system is a unique computing platform located in our department and an adaptive system, which is continuously improving for a decade.

As in other fields of science, only low scientific activities were recorded in the field of mammography during the first years after its inception in 1927. After 1960, a first, 
very modest increase in annual publication activity was observable. This development can be attributed to key improvements related to its applications and the technique itself (e.g., the vacuum film cassette), which translated into a growing scientific interest. The establishment of mammography as a screening tool was cemented in the 1980s leading to a vast number of scientific activities related to clinical trials afterwards and to annual publication rates of more than 100 articles per year. From 2011 onwards, more than 400 annual articles were identified. When we related the annual publication output to key articles in the field (identified by citation count) we could deduce main topics of interest. 16 articles with more than 500 citations were published from 1985 onwards (Table 2). Eight of these reported the findings of large screening trials whereas the remaining were dedicated to topics such as mammographic features and cancer risk prediction, digital techniques or diagnostic accuracy of mammography compared to other screening approaches. These key topics are also reflected in our analysis of main key words (Figure 6).

When the publishing institutions were analyzed, it became clear that US-American institutions dominate mammography research. Only limited data is available on the global research patterns related to other diseases and conditions observed in females. Several studies addressed smoking in pregnancy, gestational diabetes and cesarean section, with the US, the UK, Germany and Canada being among the leading countries (39-41). The results of these studies showed a comparable country-specifc publication pattern to our findings for mammography research. This pattern of activity was also reported for breast cancer (16). Here, US-American authors dominated the field with 77,101 breast cancer-related items and 2,389,337 citations (16) followed by their colleagues from the UK. While the total research activities may not be compared due to differences in the study set up (i.e., time period and search criteria), it is obvious that the most active countries are the same in breast cancer and mammography research. However, subject area analysis of single countries provided interesting countryspecific insights. In particular, Australia - which is ranked 8th in global mammography research and 9th in global breast cancer research (16)—appeared to be a country with a strong interest in the epidemiologic assessment of the technique. Country-specific differences in global research activities were also analyzed in over five million research publications (42). Within 21 organ systems, a clear dichotomy was identified which was present between Eastern and Western high-income countries (42). In contrast to the present findings on mammography research, the global research power study found Japan being ranked second (for mammography ranked only $12^{\text {th }}$ ), followed by Germany and the UK (42). Even more interesting is our gender analysis concerning Japan: Whereas most countries with a high research activity show more or less a balance between male and female authors, Japan has a male to female ratio of 2.9 , clearly indicating a gender imbalance towards male authors, i.e., in contrast to US-American authors with a ratio of 0.83 . This finding is not unique to the field of mammography research. It was verified in numerous other areas of science, technology, engineering and mathematics and is linked to specific cultural conventions in Japan (43).

Overall, patterns of country-specific publication activity on "mammography" and "breast cancer" $(16,17)$ were not only similar but also paralleled prevalence rates. Prominent scientific power players were located in North America, Australia, and Europe, where breast cancer is a relevant public health issue. In contrast, African and Asian countries were characterized by minimal contributions but also low incidence rates of breast cancer. Also, South American countries were minimized on the map of mammography research. In these countries, other disease entities are in the focus of national authors. For example, when infectious diseases were analyzed for research output, countries such as Brazil take positions among the top ten countries, as demonstrated for toxoplasmosis (25), or tuberculosis (44). However, we deduce from these findings that countries, whose inhabitants are burdened by breast cancer, actually do research to address this issue. But South-American countries, where breast cancer is a leading cause of cancer death in women, do not particularly focus on mammography-related research. This is a major shortcoming. Furthermore, we also conclude from our subject area analysis that important fields such as public health should be fostered to address breast cancer detection on a broad population scale. When focusing on socioeconomic features, the country-specific mammography research activities can be related to figures such as GDP or population metrics (which can serve as proxies for economic capabilities to invest in research and scientific manpower). In contrast to studies addressing other areas of medicine, we found for mammography that the US retained a very good position-regardless of its highest GDP or its high number of its population in relation to other high-income countries. When other countries with a high population and high total GDPs such as China or India are analyzed, it is evident that 
their relative contribution to mammography research is very small in $\mathrm{P} 1$, whereas their increasing contribution in P2 was clearly observable.

The debate if and how much women benefit from regular mammography screening is still ongoing as reflected by the numerous diverging guidelines issued by international specialist societies such as the Swiss Medical Board, the American Cancer Society or the US Preventive Services Task Force (45) (46,47). Also, many research questions remain unanswered related to the financial and psychological burden of tumour overdiagnosis or the role of tomosynthesis in breast cancer screening (10). Hence, we call for appropriately powered multisite trials to address the most pressing issues, the establishment of international research collaborations to share resources and include countries with low scientific output as well as an increased funding volume dedicated to mammography research with a special focus on public health (41).

\section{Conclusions}

The present study represents the first concise assessment of the worldwide mammography research architecture. We evaluated the related research activity including quantitative (overall research output) and semi-qualitative aspects (citation parameters), socioeconomic features and gender issues. We depict a picture of the global mammography research activity over the last century, which largely follows economic figures and prevalence rates but displays distinct differences in comparison to other biomedical entities.

\section{Acknowledgments}

Funding: None.

\section{Footnote}

Conflicts of Interest: All authors have completed the ICMJE uniform disclosure form (available at http://dx.doi. org/10.21037/qims-19-774). The authors have no conflicts of interest to declare.

Ethical Statement: Ethical approval and informed consent are not required since this is a non-human study.

Open Access Statement: This is an Open Access article distributed in accordance with the Creative Commons Attribution-NonCommercial-NoDerivs 4.0 International
License (CC BY-NC-ND 4.0), which permits the noncommercial replication and distribution of the article with the strict proviso that no changes or edits are made and the original work is properly cited (including links to both the formal publication through the relevant DOI and the license). See: https://creativecommons.org/licenses/by-nc-nd/4.0/.

\section{References}

1. Siegel RL, Miller KD, Jemal A. Cancer Statistics, 2017. CA Cancer J Clin 2017;67:7-30.

2. Ferlay J SI, Ervik M, Dikshit R, Eser S, Mathers C, Rebelo M, Parkin DM, Forman D, Bray, F. GLOBOCAN 2012 v1.0, Cancer Incidence and Mortality Worldwide. IARC Cancer Base, 2012.

3. Forman D, Bray F, Brewster DH, Gombe Mbalawa C, Kohler B, Piñeros M, Steliarova-Foucher E, Swaminathan R, Ferlay J. Cancer Incidence in Five Continents, Vol. X. IARC Scientific Publication, 2014.

4. Colditz GA, Bohlke K. Priorities for the primary prevention of breast cancer. CA Cancer J Clin 2014;64:186-94.

5. Lauby-Secretan B, Scoccianti C, Loomis D, BenbrahimTallaa L, Bouvard V, Bianchini F, Straif K. Breast-cancer screening--viewpoint of the IARC Working Group. N Engl J Med 2015;372:2353-8.

6. Gallager HS, Martin JE. The study of mammary carcinoma by mammography and whole organ sectioning. Early observations. Cancer 1969;23:855-73.

7. Martin JE, Gallager HS. Mammographic diagnosis of minimal breast cancer. Cancer 1971;28:1519-26.

8. Moskowitz M, Russell P, Fidler J, Sutorius D, Law EJ, Holle J. Breast cancer screening. Preliminary report of 207 biopsies performed in 4, 128 volunteer screenees. Cancer 1975;36:2245-50.

9. Løberg M, Lousdal ML, Bretthauer M, Kalager M. Benefits and harms of mammography screening. Breast Cancer Res 2015;17:63.

10. Friedewald SM, Rafferty EA, Rose SL, Durand MA, Plecha DM, Greenberg JS, Hayes MK, Copit DS, Carlson KL, Cink TM, Barke LD, Greer LN, Miller DP, Conant EF. Breast cancer screening using tomosynthesis in combination with digital mammography. JAMA 2014;311:2499-507.

11. Hong SJ, Yoon DY, Lim KJ, Moon JY, Yoon SJ, Seo YL, Yun EJ. Radiological Clinical Practice Guidelines Published in the Last Decade: A Bibliometric Analysis. J Belg Soc Radiol 2019;103:37. 
12. West E, Mutasa S, Zhu Z, Ha R. Global Trend in Artificial Intelligence-Based Publications in Radiology From 2000 to 2018. AJR Am J Roentgenol 2019;213:1204-6.

13. Kim ES, Yoon DY, Kim HJ, Lee K, Kim Y, Bae JS, Lee $\mathrm{JH}$. The most mentioned neuroimaging articles in online media: a bibliometric analysis of the top 100 articles with the highest Altmetric Attention Scores. Acta Radiol 2019;60:1680-6.

14. IMF. World Economic Outlook Database. 2015. Available online: http://www.imf.org/external/pubs/ft/weo/2015/02/ weodata/index.aspx

15. Yang DW, Wang XP, Wang ZC, Yang ZH, Bian XF. A scientometric analysis on hepatocellular carcinoma magnetic resonance imaging research from 2008 to 2017. Quant Imaging Med Surg 2019;9:465-76.

16. Glynn RW, Scutaru C, Kerin MJ, Sweeney KJ. Breast cancer research output, 1945-2008: a bibliometric and density-equalizing analysis. Breast Cancer Res 2010;12:R108.

17. Healy NA, Glynn RW, Scutaru C, Groneberg D, Kerin MJ, Sweeney KJ. The h index and the identification of global benchmarks for breast cancer research output. Breast Cancer Res Treat 2011;127:845-51.

18. Kusma B, Scutaru C, Quarcoo D, Welte T, Fischer TC, Groneberg-Kloft B. Tobacco control: visualisation of research activity using density-equalizing mapping and scientometric benchmarking procedures. Int J Environ Res Public Health 2009;6:1856-69.

19. Scutaru C, Quarcoo D, Sakr M, Shami A, Al-Mutawakel K, Vitzthum K, Fischer TC, Zuberbier T, GronebergKloft B. Density-equalizing mapping and scientometric benchmarking of European allergy research. J Occup Med Toxicol 2010;5:2.

20. Groneberg DA, Klingelhöfer D, Brüggmann D, Scutaru C, Fischer A, Quarcoo D. New quality and quantity indices in science (NewQIS): results of the first decade-project progress review. Scientometrics 2019;121:451-78.

21. Brock J. Women edged out of last-named authorships in top journals A Prestige Index exposes the gender bias in author lists published in top science journals. Available online: https://www.natureindex.com/news-blog/womenedged-out-of-last-named-authorships-in-top-journals

22. Götting M, Schwarzer M, Gerber A, Klingelhofer D, Groneberg DA. Pulmonary Hypertension: Scientometric Analysis and Density-Equalizing Mapping. PLoS One 2017;12:e0169238.

23. Schöffel N, Bendels MH, Groneberg DA. Ulcerative colitis: A scientometric approach to the global research output and network. Eur J Intern Med 2016;34:e41-3.

24. Brüggmann D, Elizabeth-Martinez A, Klingelhofer D, Quarcoo D, Jaque JM, Groneberg DA. Endometriosis and its global research architecture: an in-depth densityequalizing mapping analysis. BMC Womens Health 2016;16:64.

25. Brüggmann D, Handl V, Klingelhofer D, Jaque J, Groneberg DA. Congenital toxoplasmosis: an in-depth density-equalizing mapping analysis to explore its global research architecture. Parasit Vectors 2015;8:646.

26. Scutaru C, Quarcoo D, Takemura M, Welte T, Fischer TC, Groneberg-Kloft B. Density-equalizing mapping and scientometric benchmarking in Industrial Health. Ind Health 2010;48:197-203.

27. Brüggmann D, Lohlein LK, Louwen F, Quarcoo D, Jaque J, Klingelhofer D, Groneberg DA. Caesarean Section--A Density-Equalizing Mapping Study to Depict Its Global Research Architecture. Int J Environ Res Public Health 2015;12:14690-708.

28. Brüggmann D, Berges L, Klingelhofer D, Bauer J, Bendels M, Louwen F, Jaque J, Groneberg DA. Polycystic ovary syndrome: analysis of the global research architecture using density equalizing mapping. Reprod Biomed Online 2017.

29. Hirsch JE. An index to quantify an individual's scientific research output. Proc Natl Acad Sci U S A 2005;102:16569-72.

30. Hirsch JE. Does the $\mathrm{H}$ index have predictive power? Proc Natl Acad Sci U S A 2007;104:19193-8.

31. Brüggmann D, Maule LS, Klingelhofer D, Schoffel N, Gerber A, Jaque JM, Groneberg DA. World-wide architecture of osteoporosis research: density-equalizing mapping studies and gender analysis. Climacteric 2016;19:463-70.

32. Brüggmann D, Pulch K, Klingelhofer D, Pearce CL, Groneberg DA. Ovarian cancer: density equalizing mapping of the global research architecture. Int J Health Geogr 2017;16:3.

33. Groneberg-Kloft B, Dinh QT, Scutaru C, Welte T, Fischer A, Chung KF, Quarcoo D. Cough as a symptom and a disease entity: scientometric analysis and densityequalizing calculations. J Investig Allergol Clin Immunol 2009; 19:266-75.

34. Brüggmann D, Wagner C, Klingelhofer D, Schoffel N, Bendels M, Louwen F, Jaque J, Groneberg DA. Maternal depression research: socioeconomic analysis and densityequalizing mapping of the global research architecture. Arch Womens Ment Health 2017;20:25-37.

35. Gastner MT, Newman ME. Diffusion-based method for 
producing density-equalizing maps. Proc Natl Acad Sci U S A 2004;101:7499-504.

36. CIA. The World Factbook. www.cia.gov/library/ publications/the-world-factbook.

37. Carl J, Schwarzer M, Klingelhoefer D, Ohlendorf D, Groneberg DA. Curare--a curative poison: a scientometric analysis. PLoS One 2014;9:e112026.

38. Groneberg DA, Schilling U, Scutaru C, Uibel S, Zitnik S, Mueller D, Klingelhoefer D, Kloft B. Drowning--a scientometric analysis and data acquisition of a constant global problem employing density equalizing mapping and scientometric benchmarking procedures. Int J Health Geogr 2011;10:55.

39. Mund M, Kloft B, Bundschuh M, Klingelhoefer D, Groneberg DA, Gerber A. Global research on smoking and pregnancy-a scientometric and gender analysis. Int J Environ Res Public Health 2014;11:5792-806.

40. Brüggmann D, Richter T, Klingelhofer D, Gerber A, Bundschuh M, Jaque J, Groneberg DA. Global architecture of gestational diabetes research: densityequalizing mapping studies and gender analysis. Nutr J 2016;15:36.

41. Pisano ED, Yaffe MJ. Breast cancer screening: should tomosynthesis replace digital mammography? JAMA 2014;311:2488-9.

Cite this article as: Brüggmann $\mathrm{D}$, Grimstein $\mathrm{M}$, Solbach C, Klingelhöfer D, Bendels MHK, Jaque J, Groneberg DA. Mammography: density equalizing mapping of the global research architecture. Quant Imaging Med Surg 2021;11(1):143-161. doi: 10.21037/qims-19-774
42. Groneberg-Kloft B, Scutaru C, Kreiter C, Kolzow S, Fischer A, Quarcoo D. Institutional operating figures in basic and applied sciences: scientometric analysis of quantitative output benchmarking. Health Res Policy Syst 2008;6:6.

43. Osumi N. Calling rikejo - A push for more Japanese women of science. Nature 2018;555:S59.

44. Groneberg DA, Weber E, Gerber A, Fischer A, Klingelhoefer D, Brueggmann D. Density equalizing mapping of the global tuberculosis research architecture. Tuberculosis (Edinb) 2015;95:515-22.

45. Oeffinger KC, Fontham ET, Etzioni R, Herzig A, Michaelson JS, Shih YC, Walter LC, Church TR, Flowers CR, LaMonte SJ, Wolf AM, DeSantis C, Lortet-Tieulent J, Andrews K, Manassaram-Baptiste D, Saslow D, Smith RA, Brawley OW, Wender R. Breast Cancer Screening for Women at Average Risk: 2015 Guideline Update From the American Cancer Society. JAMA 2015;314:1599-614.

46. Biller-Andorno N, Jüni P. Abolishing mammography screening programs? A view from the Swiss Medical Board. N Engl J Med 2014;370:1965-7.

47. Siu AL. Screening for Breast Cancer: U.S. Preventive Services Task Force Recommendation Statement. Ann Intern Med 2016;164:279-96. 